\title{
The effect of fluorine on reaction rim growth dynamics in the ternary $\mathrm{CaO}$ -

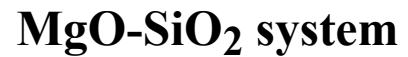

\author{
MEES GIJSBERT FRANKE AND BASTIAN JOACHIM- \\ MROSKO
}

University of Innsbruck

Presenting Author: mees.franke@uibk.ac.at

Growth of reaction rims is mainly controlled by a change in physical parameters such as pressure and temperature, a change in the chemical composition of the system and/or by the presence of volatiles. In particular, the effect of volatiles other than water on reaction rim growth remains poorly understood. In order to accurately model metamorphic and metasomatic processes, a quantification of the effect of volatiles on reaction-rim growth dynamics is necessary.

In this study, we investigated the effect of fluorine on reaction rim growth dynamics in the ternary $\mathrm{CaO}-\mathrm{MgO}-\mathrm{SiO}_{2}$ system. A series of piston cylinder experiments were conducted at upper mantle P-T conditions of $1000{ }^{\circ} \mathrm{C}$ and $1.5 \mathrm{GPa}$. In each experiment, reaction rims were grown for 20 minutes between a natural wollastonite crystal and $\mathrm{MgO}$ powder matrix with the addition of up to $10 \mathrm{wt} \%$ fluorine.

Results show an increase in overall rim thickness from 12.50 (146) $\mu \mathrm{m}$ in the fluorine-free system to 105.49 (185) $\mu \mathrm{m}$ in experiments with a bulk fluorine content of $10 \mathrm{wt} \%$. In the fluorine free system, we produced a rim sequence of wo $\mid$ mer $\mid$ di | fo | per, complying with phase stabilities at water saturated conditions. As soon as $0.1 \mathrm{wt} \%$ fluorine was introduced into the system, humite group minerals (HGMs) and monticellite were stabilized resulting in the multilayer rim sequence wo $\mid$ mer $\mid$ mon | fo + HGMs | per. In experiments with fluorine concentrations $>1 \mathrm{wt} \%$, cuspidine is stabilised and represents the major fluorine sink. Additionally, the transition from a monomineralic layer sequence to a palisade microstructure with alternating diopside and cuspidine lamellae at $>1 \mathrm{wt} \% \mathrm{~F}$ suggests that fluorine affects the phase organisation within the reaction rim.

Our results illustrate the significance of fluorine during nettransfer reactions, where its presence changes phase stabilities and relative component mobilities. This implies not only that reaction rims may be used as a tool to infer the amount of fluorine present during metamorphic reactions, but also that we need to consider the role of fluorine for a correct interpretation of the P-T-t history of metamorphic rocks. 